\title{
A DEBATE ON THE SIMILARITY OF PARTICLE SIZING RESULTS DERIVED FROM THE ANALYSIS OF FINE- GRAINED SEDIMENTS BY TWO DIFFERENT INSTRUMENTATIONS
}

\section{Iatrou M. ${ }^{1}$, Papatheodorou G. ${ }^{1}$, Piper D. J. W. ${ }^{2}$, Tripsanas E. ${ }^{2}$, and Ferentinos G. ${ }^{1}$}

\author{
${ }^{1}$ Laboratory of Marine Geology \& Physical Oceanography, Department of Geology, University of \\ Patras, 26500,Rio, Patras, Greece, iatroum@upatras.gr \\ ${ }^{2}$ Geological Survey of Canada (Atlantic), Bedford Institute of Oceanography, P.O. Box 1006, \\ Dartmouth, Nova Scotia B2Y 4A2, Canada
}

\begin{abstract}
A set of grab-sample sediments collected from the basin floor of the Corinth Gulf, Greece, was analysed using two different techniques; LS 230 laser system and Coulter Counter TA II. The present study presents the results derived from the comparison between the two techniques. The correlation between the mean size and the sorting values obtained from the two methods is moderate. Also moderate are the correlations estimated for the fractions of clay and silt obtained from the two methods Furthermore the analysis showed that the Laser Coulter determines coarser grain sizes than the Coulter. The analysis of variation/residuals within individual size intervals showed a higher variability of residuals for the coarser fractions (7-6 and 5-4 phi).
\end{abstract}

Key words: electronic particle counting, laser diffractometry.

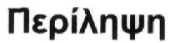

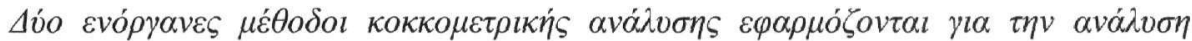

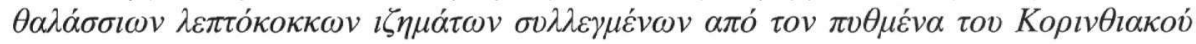

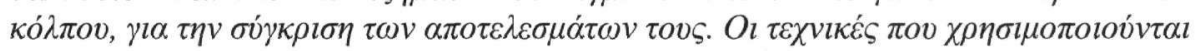

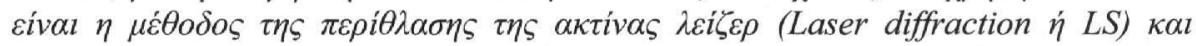

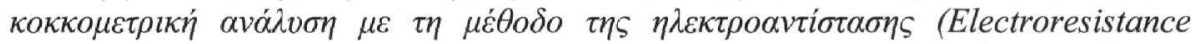

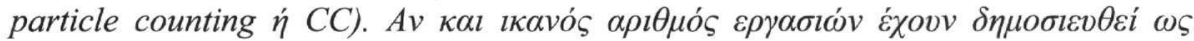

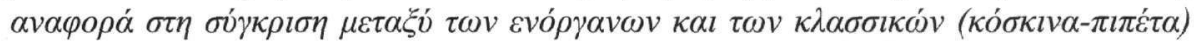

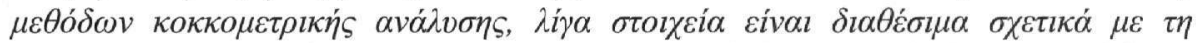

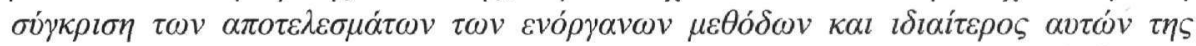

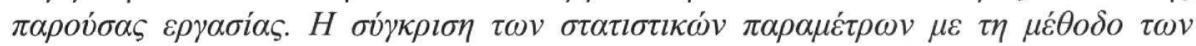

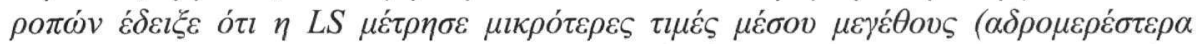

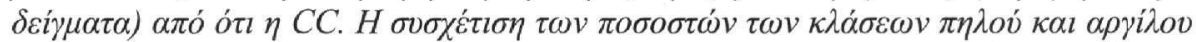

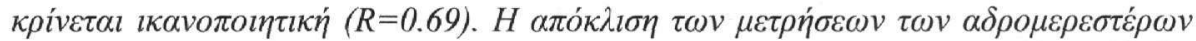

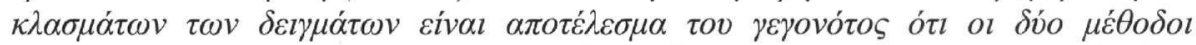

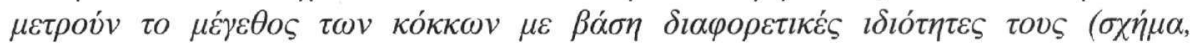




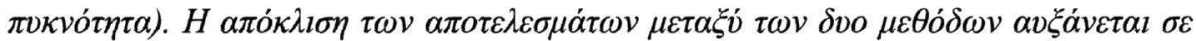

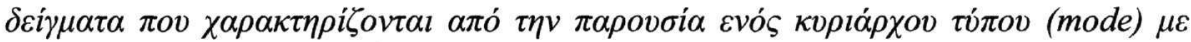

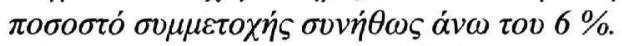

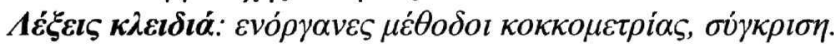

\section{Introduction}

Particle size is a fundamental property of sedimentary materials providing important information about their provenance, transport history and depositional conditions. So far a variety of traditional technologies have been used for the determination of particle size in clay to sand-sized sediments. These include analysis by settling tube, sieve and pipette (Beuselinck et al. 1998). Each technique defines the size of a particle in a different way and thus measures different properties of the same material (Konert and Vandenberghe 1997). The pipette method, suitable only for the finer fractions (less that $63 \mu \mathrm{m}$ diameter), defines the "Stokes" particle diameter as equivalent to that of a sphere settling in the same liquid with the same speed as the unknown sized particle. The sieve defines a particle diameter as the length of the side of a square hole through which the particle pass and this method is mainly suitable for the analysis of sand and gravel -sized materials (greater than $63 \mu \mathrm{m}$ diameter). Via sieving methods, the grains are separated and a weight-based size distribution is constructed.

Modern methods involve instrumental techniques which are more rapid than the contemporary ones. In these modern methods are included the particle sizing by electrical sensing (Bianchi et al. 1999), X-ray absorption (Singer et al. 1988), X-ray attenuation (Stain 1985) and hydrophotometer (Jordan et al. 1971). There was also an attempt to apply image-based granulometries to estuarine and marine sediments as a alternative to sieve and coulter counter method (Balagurunathan et al. 2001, Frančišković-Bilinski et al. 2003). A "Laser diffraction spectrophotometer" which is capable of analyzing a wide range of particles (from clay to sands), measures a particle diameter as equivalent to a sphere that exhibits the same diffraction as the particle. The Sedigraph system senses particle size based on it's settling characteristics. The resistance pulse Counter defines the size of a particle according to its volume. Both the latter two methods are best suited to analyze finer sediments (silt and clay size). The hydrophotometer measures the percentage of transmitting light which passes through a particle suspension and determines the amount of material that has settled. Morphological-granulometric sizing is based on shape area (binary image) or volume (gray scale image).

The application of modern techniques such as Laser diffraction and Electrozone sensing has raised questions about the similarity of the results derived from the above methods. McCave et al. (1986), Singer et al. (1988), Syvitski et al. (1991), Konert and Vandenberghe (1997), Buurnman et al. (1997), Loizeau et al. (1994), Muggler et al. (1997), Beuselinck et al. (1999), McCave et al. (2006) have compared the above mentioned instrumental techniques with the classical leading occasionally to conflicting results. However it should be mentioned that only a few works have studied the relation between the laser diffractometry and electozone particle counting (e.g.: Singer et al. 1988, Loizeau et al. 1994).

The present study aims at contributing further in the above studies by comparing two data sets of particle distributions derived from two different analytical techniques; laser granulometry and electroresistance counting. Data sets consist of grain size distributions that occurred in the fine grained size fraction.

\section{Materials and Methods}

\subsection{The Dataset}

A dataset of twenty-eight closely related marine sediment samples, in terms of origin and grain size, were analyzed for particle size determination by two methods: laser diffractometry and 
electronic particle counting. The samples come from surface and subsurface sediments collected by Day-grab sampler, from the basin of Corinth Gulf, Greece, at a water depth of $850 \mathrm{~m}$ (Iatrou et al. 2006). The recent sedimentary cover of the studied area is characterized by the presence of metalliferous tailing disposals derived from an aluminum processing plant and the intercalating natural sedimentation deposits. Structures observed in the sediment samples suggested that the red-mud and the natural mud layers have been deposited by gravity induced flows (Varnavas et al. 1986, Papatheodorou et al. 2003, Iatrou et al. 2006). The dataset consists of subsurface samples which were sub-sampled from six short cores, typical of the sedimentary types composing the modern sedimentological regime (Iatrou et al. 2006). They represent all the types of sediments in the area: from natural to red-mud deposits. Previous studies from the study area (Papatheodorou et al. 2003, Iatrou et al. 2006) showed the fine-grained texture of the sediments and therefore the samples were examined with interest focused on the silt and clay size range.

\subsection{Determination of Particle -Size Distribution}

\subsubsection{Laser Diffractometry}

Low angle laser light scattering (LALLS, commonly called laser diffraction) system (LS) pass a laser beam of known wavelength through a suspension of the material to be analyzed and measures the angular distribution and intensity of the forward -scattered (diffracted) light by the particles in suspension. A theoretical model based on diffraction of particles with particular properties and grain-size distribution, is then fitted to the actual diffraction results. (Sperazza et al. 2004). The two main diffraction theories which are typically used in the prediction of laser particle results are the Fraunhofer theory and Mie theory.

Particle size analysis was performed with a Beckman-Coulter LS-230 laser granulometer, equipped with a 750-nm laser beam and 126 photodiode detectors. The instrument measures volume \% in 92 fractions ranging from 0.4 to $2000 \mu \mathrm{m}$ corresponding to an interval $0.13 \varnothing$. Fraunhofer mathematical model was used by default to calculate the size of particles based on the concentric ring pattern of light-scatter from the laser beam. Mc Cave et al. (1986), Singer et al. (1988) and Loizeau et al. (1994) argue that the particulate model tends to underestimate particle sizes close to the wavelength of the laser source light.

Each sediment sub-sample was suspended in $10 \mathrm{ml}$ of deionized water and was ultrasonically dispersed for less than $5 \mathrm{~min}$. The suspension was afterwards gently poured into the fluid module filled with filtered and degassed water. The fluid circulates through the sample cell during the analysis to make sure that all particles are entrained into the flow and ensuring a random orientation of the particles. The adequate amount of sample was determined by the obscuration percentage of the laser beam through the sample cell and the recommended range was from 8 to 12 $\%$, which equates with 0.2 and 4 gr. for most sediments. Most of the samples in the present study reached the recommended obscuration levels using only a small quantity of material due to the fine texture of the sediments.

\subsubsection{Electronic Particle Counting}

The Coulter counter (CC) method has been reviewed by various researchers, i.e. Shideler (1976), Singer et al. (1988), Bianchi et al. (1999), and Molinaroli et al. (2000). The Electronic Particle counter volumetrically sizes and counts the particles suspended in a weak electrolyte that pass through a small aperture with electrodes on both sides. Particles moving through the aperture displace the electrolyte and temporarily increase the resistance between the electrodes. A constant current is maintained and the resistance changes produce voltage pulses which are amplified, sorted according to pulse height in a multichannel analyser and counted. The magnitude of the pulses is proportional to particle volume (Milligan and Kranck 1991) and the number of pulses is equal to particle concentration. 
The instrument used for the present analysis is a Coulter Counter model TA II. Tubes with 30- $\mu \mathrm{m}$ and $200-\mu \mathrm{m}$ type apertures were used to cover the analytical range from 0.4 to $80.6 \mu \mathrm{m}$. Samples were dispersed with sodium hexametaphosphate solution and ultrasonically treated (bath) for a time not exceeding $10 \mathrm{~min}$. The analysis proceeded in two steps; firstly for the $30-\mu \mathrm{m}$ and secondly for the $200-\mu \mathrm{m}$ tube aperture. The suspension of each sample was subsampled by an automatic pipette and was wet-sieved through a $30-\mu \mathrm{m}$ sieve (or $200-\mu \mathrm{m}$ in the second stage). Afterwards the subsample was placed in a glass beaker filled with $4 \%$ sodium hexametaphosphate (Calgon) and stirred with a moderate speed. This suspension was counted until a specific number of particles was accumulated in any of the size intervals. The resulting size distributions derived from each of the two steps were combined by matching and re-computing the area under the combined curve to $100 \%$.

\subsubsection{Data Preparation and Statistical Treatment}

In this study the upper limit of the size range is different for the two devices; $80.6 \mu \mathrm{m}$ for the $\mathrm{CC}$ and $2000 \mu \mathrm{m}$ for LS. In order to compare results obtained from the two instrumentations, the distribution results of LS have been recalculated by interpolation in the 24 size classes of CC from 0.4 to $80.6 \mu \mathrm{m}$. The particle size results are expressed in volume percent in both analytical techniques, which facilitates the by-instrument comparison.

The method of moments was performed to estimate the mean and sorting of the two datasets. The higher order moments could not present any remarkable correlation between the two methods. The comparison of the results was achieved by: (i) the mean differences of frequency distribution for each of seven grain-size intervals; $>10 ; 10-9 ; 9-8 ; 8-7 ; 7-6 ; 6-5$; and $5-4 \varnothing(>1 ; 1-2 ; 2-4 ; 4-8 ; 8-16$; 16-32; and 32-63 $\mu \mathrm{m}$ ) between the two datasets, (ii) the correlation coefficient between the two bulk datasets and between the silt and the clay fractions measured by the two instrumentations and (iii) the analysis of variation/residuals within individual grain size intervals. Similar approaches have been discussed by Behrens (1978), Konert and Vandenberghe (1997), Loizeau et al. (1994) and Molinaroli et al. (2000).

\section{Results and Discussion}

The differences between the mean and sorting measures of Laser Coulter and Coulter Counter were compared using the linear phi scale (Ø) (Table 1, Fig. 1).

In the majority of the samples the mean size values (in phi) calculated by the CC method were overestimated comparing to those determined by LS. Twenty-three samples differed in the mean size by up to $1 \varnothing(500 \mu \mathrm{m})$ with higher overestimation occurred in the fine-grained samples. This overestimation of the mean size is also supported in the grain size frequency distributions curve from the $\mathrm{CC}$ analysis which showed a shift towards the fine classes comparing to laser coulter analysis (Fig. 6b). On the contrary, LS method determined larger grain sizes than CC method did up to $1 \varnothing$ in five coarse-sized samples. The sorting estimates presented smaller differences between the two methods. However the overestimated sorting values (up to $0.2 \varnothing$ or $\sim 870 \mu \mathrm{m}$ ) by the CC method concerned the fine-grained samples. Molinaroli et al. (2000) compared the statistical parameters measured by a Galai Cis-1 system (laser based optical analysis), a Coulter Counter and a Sedigraph and showed that the grain size distributions estimated by the laser system had coarser mean size and better sorting in relation to the other two methods.

The mean values of the bulk sediment samples obtained by the two instruments are compared in Figure 1(a). The values are highly scattered around the bisectrix (1:1 line) and the correlation coefficient obtained is 0.7 revealing a moderate interrelation between the laser coulter and coulter counter analysis. This moderate correlation may be due to the very small quantity of sediment involved in the Coulter Counter measurement, which is at least one order of magnitude lower than the quantity used with the laser coulter. Loizeau et al. (1994) suggested a similar explanation for the dispersion around 1:1 line. The relationship between Coulter Counter and Laser (Malvern) 
Table 1 - Coulter Counter and Laser Coulter mean size and sorting statistics

\begin{tabular}{|c|c|c|c|c|c|c|}
\hline $\begin{array}{c}\text { Sample } \\
\text { No }\end{array}$ & $\begin{array}{c}\text { Coulter } \\
\text { Counter } \\
\text { Mean } \\
\text { (phi) }\end{array}$ & $\begin{array}{c}\text { Coulter } \\
\text { Counter } \\
\text { Mean } \\
(\mu \mathrm{m})\end{array}$ & $\begin{array}{l}\text { Laser } \\
\text { Coulter } \\
\text { Mean } \\
\text { (phi) }\end{array}$ & $\begin{array}{c}\text { Laser } \\
\text { Coulter } \\
\text { Mean } \\
(\boldsymbol{\mu m})\end{array}$ & $\begin{array}{c}\text { Coulter } \\
\text { Counter } \\
\text { Sorting } \\
\text { (phi) }\end{array}$ & $\begin{array}{c}\text { Laser } \\
\text { Coulter } \\
\text { Sorting } \\
\text { (phi) }\end{array}$ \\
\hline $1 / 4$ & 8.306 & 3.159 & 7.717 & 4.751 & 1.737 & 1.491 \\
\hline $1 / 5$ & 8.427 & 2.905 & 7.804 & 4.473 & 1.569 & 1.501 \\
\hline $1 / 6$ & 8.432 & 2.896 & 8.062 & 3.741 & 1.574 & 1.541 \\
\hline $12 / 6$ & 8.457 & 2.846 & 7.617 & 5.093 & 1.604 & 1.479 \\
\hline $12 / 7$ & 8.076 & 3.707 & 7.575 & 5.244 & 1.816 & 1.432 \\
\hline $12 / 8$ & 8.452 & 2.855 & 7.551 & 5.332 & 1.667 & 1.476 \\
\hline $12 / 9$ & 8.199 & 3.403 & 7.653 & 4.968 & 1.707 & 1.501 \\
\hline $12 / 11$ & 8.253 & 3.277 & 7.609 & 5.122 & 1.685 & 1.451 \\
\hline $17 / 5$ & 7.719 & 4.745 & 7.823 & 4.416 & 1.657 & 1.736 \\
\hline $17 / 7$ & 6.448 & 11.456 & 7.360 & 6.088 & 1.586 & 1.885 \\
\hline $17 / 8$ & 7.298 & 6.355 & 6.378 & 12.023 & 1.693 & 1.848 \\
\hline $17 / 9$ & 7.597 & 5.167 & 7.077 & 7.408 & 1.774 & 2.009 \\
\hline $17 / 10$ & 7.882 & 4.239 & 7.750 & 4.646 & 1.825 & 1.798 \\
\hline $17 / 12$ & 7.936 & 4.083 & 7.997 & 3.913 & 1.767 & 1.599 \\
\hline $17 / 15$ & 7.915 & 4.144 & 7.751 & 4.643 & 1.801 & 1.836 \\
\hline $20 / 9$ & 7.879 & 4.249 & 7.945 & 4.059 & 1.655 & 1.661 \\
\hline $20 / 10$ & 6.764 & 9.204 & 6.143 & 14.148 & 1.556 & 1.748 \\
\hline $20 / 12$ & 7.882 & 4.238 & 7.703 & 4.799 & 1.854 & 1.757 \\
\hline $20 / 14$ & 6.224 & 13.375 & 6.904 & 8.349 & 2.062 & 2.117 \\
\hline $24 / 6$ & 8.253 & 3.279 & 7.803 & 4.479 & 1.644 & 1.515 \\
\hline $24 / 7$ & 7.990 & 3.934 & 7.923 & 4.119 & 1.760 & 1.556 \\
\hline $24 / 8$ & 8.037 & 3.807 & 7.512 & 5.478 & 1.845 & 1.848 \\
\hline $24 / 20$ & 7.279 & 6.441 & 6.815 & 8.882 & 1.778 & 2.030 \\
\hline $38 / 5$ & 8.250 & 3.285 & 7.886 & 4.228 & 1.737 & 1.548 \\
\hline $38 / 6$ & 8.031 & 3.824 & 7.883 & 4.235 & 1.774 & 1.540 \\
\hline $38 / 7$ & 8.084 & 3.686 & 7.716 & 4.756 & 1.765 & 1.542 \\
\hline $38 / 8$ & 8.177 & 3.454 & 7.827 & 4.402 & 1.740 & 1.583 \\
\hline $38 / 16$ & 8.350 & 3.064 & 7.812 & 4.449 & 1.631 & 1.603 \\
\hline
\end{tabular}

methods was also examined by McCave et al. (1986), who compared the modal sizes and reported that in some cases there was little correspondence between the two methods. However it was shown by studies which have compared Coulter Counter with pipette method, that the data presented a satisfactory correlation despite the fact that $\mathrm{CC}$ means were coarser than the pipette means in the finer size ranges (Shideler 1976). Furthermore Behrens (1978) which applied 
regression equation on the data sets derived from the coulter counter and pipette techniques also showed that the means had high linear correlation $(r=0.99$. slope $=0.70)$.
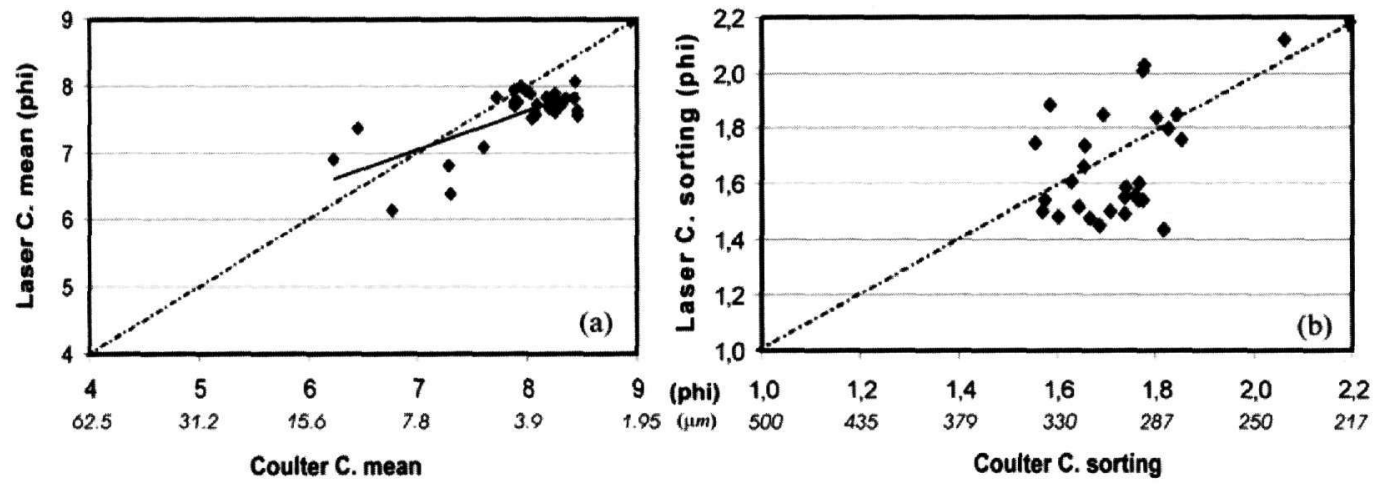

\section{Figure 1 - Comparison of statistical parameters of two data sets (a) mean size and (b) sorting. Dashed line represents 1:1}

The distribution of mean values differences of the two methods in specific grain size intervals are presented in Figure 2. The greater dissimilarities obsereved in the finer $(>10 \varnothing)$, the 10-9 Ø (1-2 $\mu \mathrm{m})$ and the 8-7 $\varnothing(4-8 \mu \mathrm{m})$ intervals. For the finest two intervals $(>10 \varnothing .10-9 \emptyset)$, the Laser Coulter measures are higher than the Coulter Counter by $\sim 4 \%$ and $\sim 8 \%$, respectively. The Coulter Counter detects fewer particles than Laser Coulter by almost $7 \%$ for the $8-7 \varnothing$ internal. In the 7-6 Ø $(8-16 \mu \mathrm{m})$ and in the coarsest $(5-4 \varnothing)$ intervals the frequency distribution of Laser Coulter is overestimated by $\sim 3 \%$.

The above suggest that the results from the Laser Coulter instrument are shifted towards coarse fractions, and the Coulter Counter overestimates the fine fractions. This could be attributed to particle shape. Jonasz (1991) argued about the influence of particle shape on the grain size analysis and suggested that the projected area of non-spherical particle orientation is larger than that of a sphere with equal volume. Konert and Vanderberghe (1997) compared the Laser Coulter with the pipette-sieve method and also reported that laser method led to coarser results.

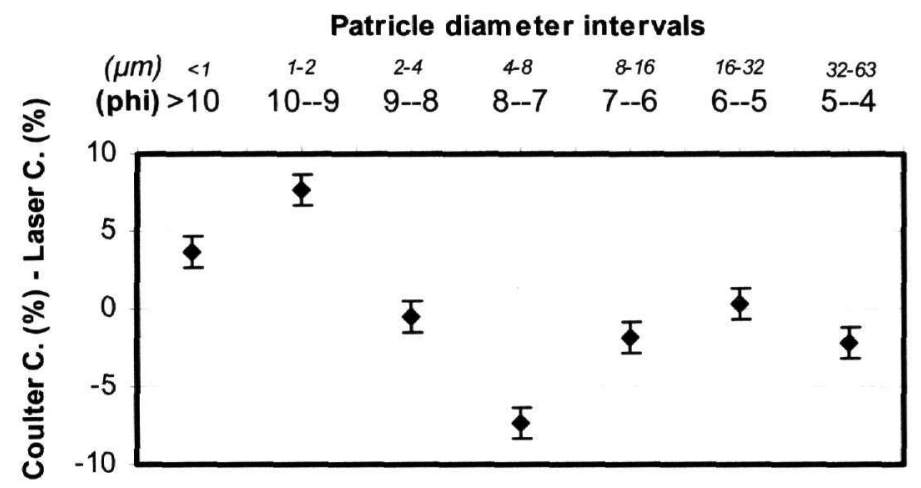

Figure 2 - Mean differences between frequencies for grain size intervals reported in $\mathbf{x}$-axis

The relevance of the data obtained by the two instruments was also examined by treatment of variation/residuals analysis within individual grain-size intervals. The residuals constitute normalized factors which are independent from the magnitude of the frequency in the considered 
grain size interval. In the present study the residual values between Coulter Counter and Laser Coulter were derived from the formula applied by Molinaroli et al. (2000):

Residual values $=($ Coulter Counter \% - Laser Coulter \% $) /$ Coulter Counter \%

Residual values were plotted against Laser Coulter data for seven grain size fractions $(>10 ; 10-9$; $9-8 ; 8-7 ; 7-6 ; 6-5 ;$ and $5-4 \varnothing)$. Linear regression was applied to the scattered plots and correlation coefficient was computed for each size interval. Figure 3 illustrates the correlation between residual values and Laser Coulter data for selected grain size fractions. The $>10,10-9$ and $6-5 \varnothing$ fractions are not presented here due to the poor correlation observed.
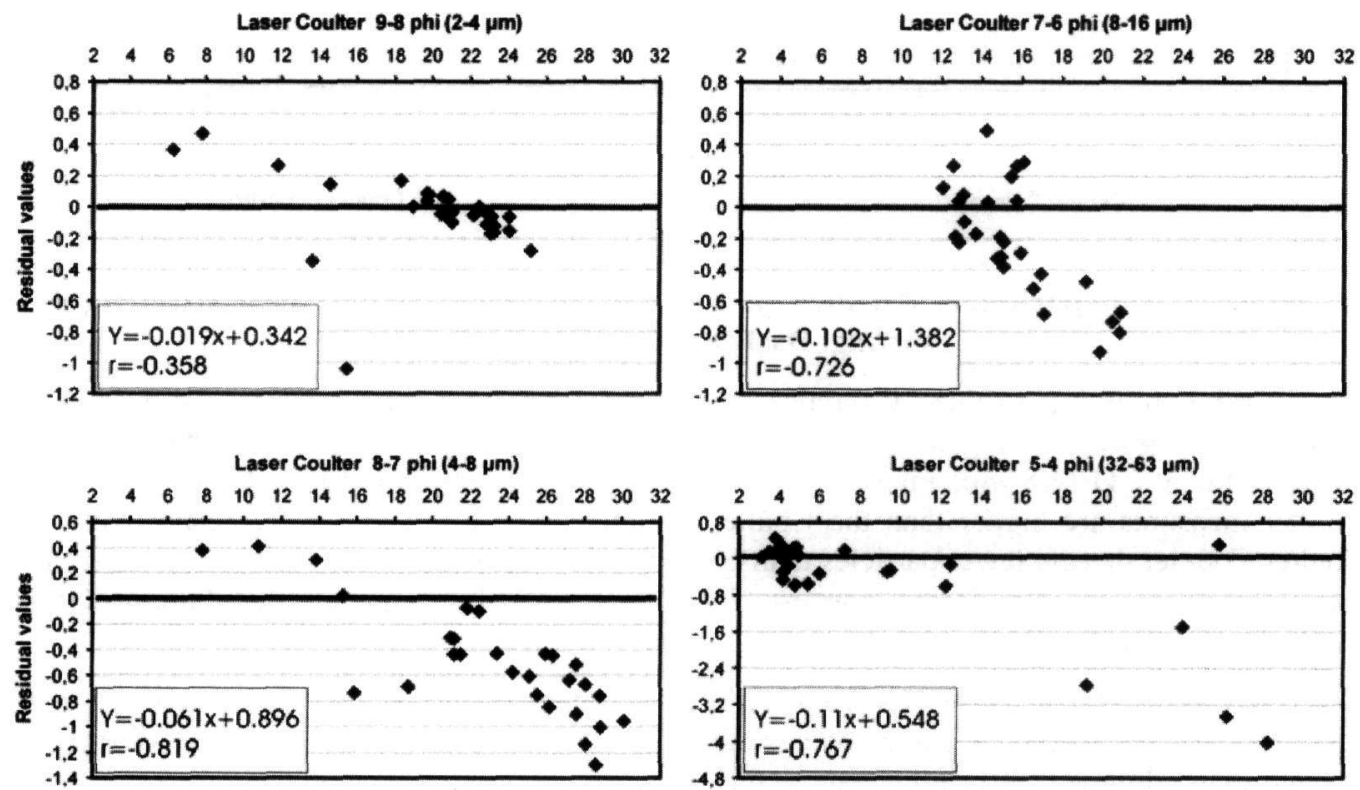

Figure 3 - Residual values plotted vs Laser Coulter selected fractions

In the plots of Figure 3 residual values were almost linearly related to Laser Coulter data in the 8-7 $\varnothing(4-8 \mu \mathrm{m})(\mathrm{r}=-0.819 ;$ slope $=-0.061)$. The correlation coefficient decreased in the 7-6 Ø $(8-16$ $\mu \mathrm{m})(\mathrm{r}=-0.726$; slope $=-0.102)$ and 5-4 Ø $(32-63 \mu \mathrm{m})(\mathrm{r}=-0.767$; slope $=-0.11)$ intervals where there was a corresponding increase in the slope which indicated an enhance in the variability of the residuals. Significant correlation was not found in the 9-8 Ø (2-4 $\mu \mathrm{m})$ interval.

The increase in the variability of the residuals in the coarser grain size intervals (7-6 and 5-4 Ø) may indicate a grater heterogeneity of physical properties (shape and density) of particles. This suggestion is further supported by the findings of Molinaroli et al. (2000).

Further comparison between silt and clay fractions obtained by the two methods showed that CC method yield a lower silt fraction than the LS method (Fig. 4). Conversely the clay fraction is overestimated by the $\mathrm{CC}$ method. The relationships found between the Laser Coulter and the Coulter Counter derived data for the two size fractions present moderate correlation coefficients $(\sim$ 0.69) and a fairly wide scatter of the points around the fitted line. McCave et al. (1986) which examined the efficiency of Malvern Laser system to determine clay fraction reported that the Laser method measured only a small fraction of clay present. 

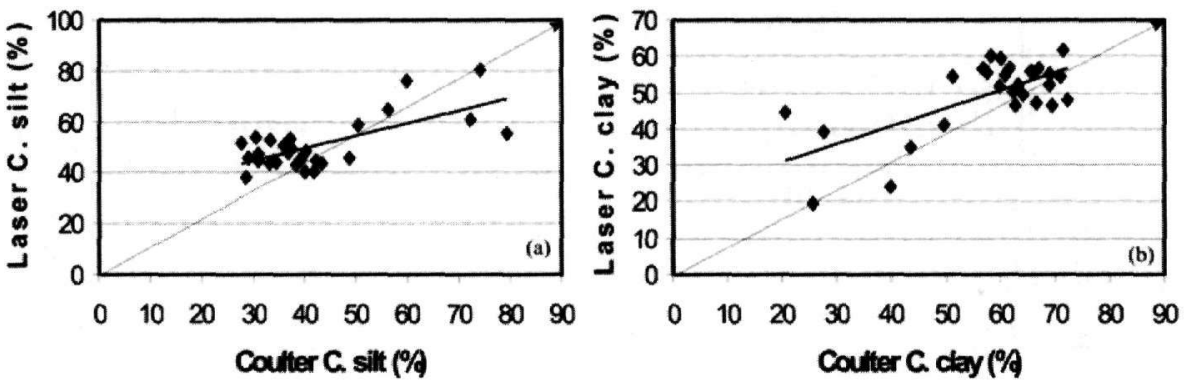

\section{Figure 4 - Comparison of (a) silt and (b) clay fractions}

The above mentioned discrepancies between the two methods may be due to the artificial truncation of the size distribution at the higher analytical limit of the tube aperture used by the Coulter Counter technique. As the size percentage data is based only on the analyzed distribution rather than on the total size distribution which is covered by the Laser Coulter method the particles larger than the tube's higher analytical limit are essentially ignored.

The moderate correlation $(\sim 0.69)$ occurred between silt fractions and clay fractions for both methods differs from previously published data which correlate satisfactory the Laser Coulter method with various techniques. Van Donger (1989) obtained a high correlation coefficient of 0.85 (slope $=0.185$ ) for the comparison between the pipette and the Laser Coulter method. In addition Konert and Vanderberghe (1997) also obtained a high correlation coefficient $(\mathrm{r}=0.957$; slope $=$ 0.361 ) for the comparison between the clay fractions obtained by Laser Coulter and pipette methods. Moreover, these authors obtained likewise high correlation for the data describing the fine-silt fraction. In a similar work, Beuselinck et al. (1998) compared the Laser diffractometry with sieve-pipette technique and showed a satisfactory correlation with $r>0.9$ in almost all the size fractions. Singer et al. (1988) assessed the accuracy of various instrumentations through two sets of standards between 4.0 and $8.0 \varnothing$. After the analysis of polymodal samples, these authors reported that Malvern Laser Sizer showed an overall broadening of individual modes. On the contrary, Coulter Counter delimited correctly the size range of individual modes. According to Singer et al. (1988) the disparity in the results for all instruments involved samples with high clay contend, in other words with increased particle-particle interface.

In a further approach of the by-instrumentation comparison, beyond the usual statistical treatment, the total set of particle size data (in volume percent) (24 size classes X 28 samples) from the Coulter Counter analysis was plotted against the results of the Laser Coulter analysis. In Figure 5 the samples that scatter more around the 1:1 line are those which presented the greater differences in the mean size. Due to the wide scattering of the data around the bisectrix a unique linear fit could not be meaningful. A threshold volume percent above which the Coulter Counter relatively underestimates particle diameters was observed. Therefore the data set was divided in two subsets; the first subset contains samples which have volume percent $<6 \%$ in the Coulter Counter and the second consists of samples with volume percents greater than $6 \%$. It should be mentioned that the selected $6 \%$ volume percent as a critical value is rather arbitrary than based on certain criteria.

On each data subset a linear regression was applied. For the first subset $(<6 \%)$ a moderate correlation was found $(r=0.75)$ between the two techniques. The Laser Coulter method slightly overestimates the volume percent for that subset. On the other hand, the two methods do not exhibit any correlation for the second subset $(>6 \%)$. As a result, the correlation between the two techniques is strongly controlled by the volume percentage distribution of the sediment sample. Figure 6 shows the particle distributions of two sediment samples, representative of the two above subsets. 


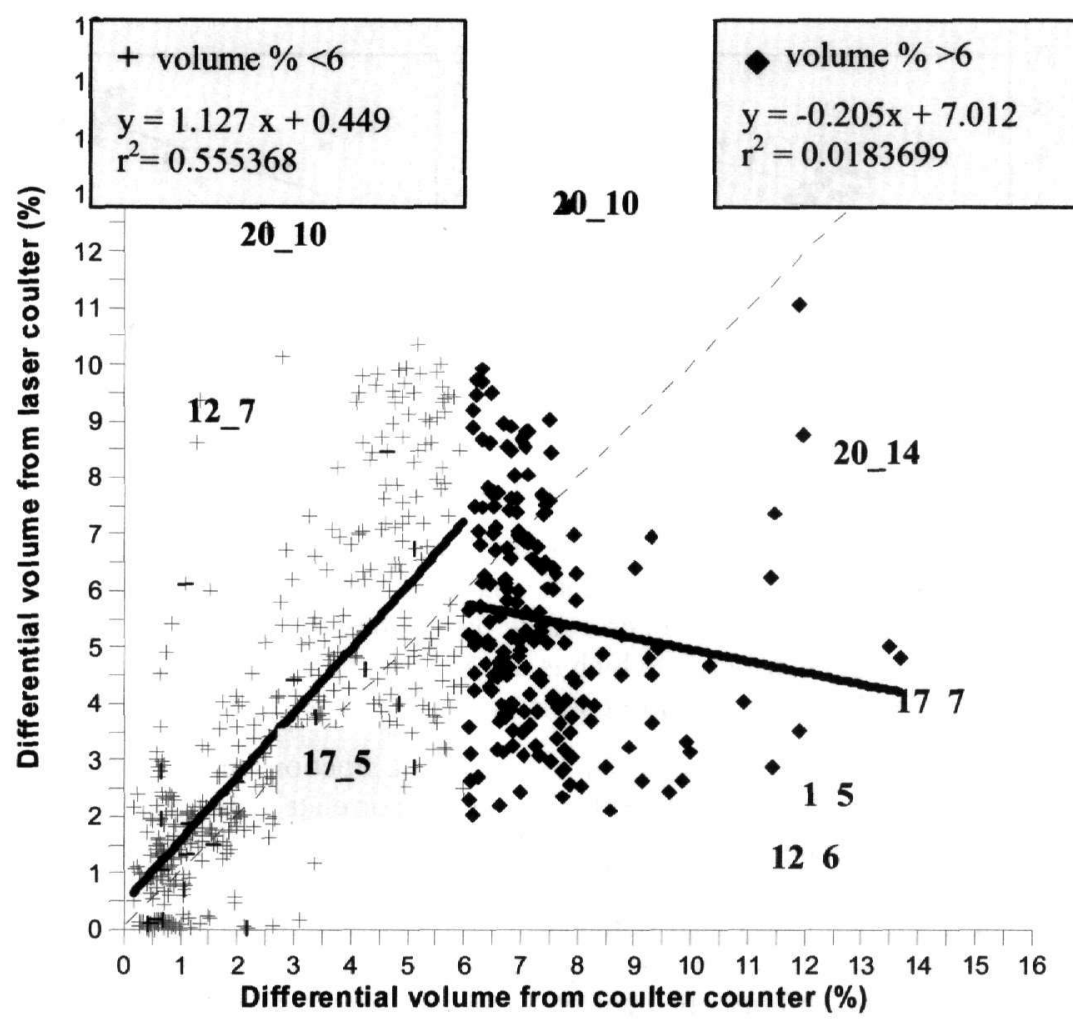

Figure 5 - Particle size distribution volume percents for each sample in each size fraction

The sample $17 / 5$ has a platykurtic distribution without a profound modal size (Fig. 6a). It represents a typical particle distribution for the first data subset containing low percentages (less than $6 \%$ ) for each particle size class. The two particle distributions derived from the two techniques present almost the same pattern.

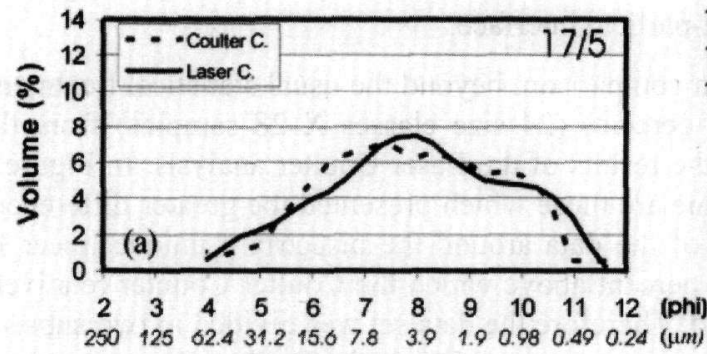

Particle diameter

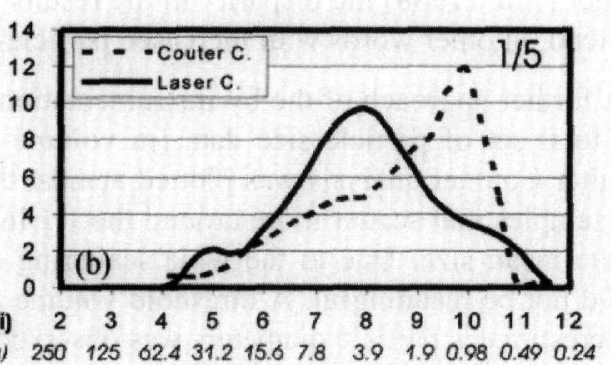

Particle diameter

Figure 6 - Typical particle distributions of samples (a) 17/5 and (b) 1/5

The sample $1 / 5$ shows a leptokurtic grain size distribution with a modal size $(12 \%$. $10 \emptyset$ for the $\mathrm{CC}$ analysis) and it is considered to be a typical member of the second subset. The analysis of sample with both instruments indicated that the Coulter Counter overestimated the high volume percentage size fractions.

The existence of a threshold percentage was also reported by Beuselinck et al. (1998). These authors reported that the Coulter Laser method gives greater values than the sieve-pipette method 
for most size fractions, but only up to certain percentage, above which fractions are relatively underestimated by the Laser method.

It should be noted that an additional reason for the discrepancy between the two methods may also be the analytical procedure. The Laser Coulter instrument performs measurement in the whole size range of the sample at the same time. On the contrary, the Coulter Counter analysis involves the combination and overlapping of the results derived form the two separate steps, which is sometimes inaccurate. The above suggestion is further considered as a limitation of the electronic counting (CC) method by McCave and Syvitski (1991).

\section{Conclusions}

The present study compares the particle size distributions measured by the Coulter Counter and Laser Coulter methods applied on 28 fine-grained red-mud tailing and natural sediment samples. The examination of the by-instrument relationship was achieved by (i) comparing the statistical parameters (mean size and sorting), (ii) calculating the mean differences in frequency distributions for specific grain-size intervals between the two datasets, (iii) applying correlation coefficient method between the silt and clay fractions of the two datasets and (iv) performing analysis of variation/residuals within individual grain size intervals.

The relationships between the two techniques for the moment statistical parameters and the silt and clay fractions differed from those appearing in the literature. However, it should be mentioned that previously published works have suggested various levels of relationships between the Laser Coulter and Coulter Counter results, ranging from poor to high correlation. As it is also the case for most comparisons performed between particle sizing techniques. The comparison of statistical parameters was carried out considering only the analytical range common to two instruments, with an interpolation of laser data according to coulter range.

The comparison of moment statistics demonstrated that Laser Coulter determined coarser grain sizes than Coulter Counter, especially in the coarser-grained samples. On the contrary, Coulter Counter instrumentation overrated the clay fraction.

Coarser fraction data present greater variability between the two instruments due to heterogeneity of particles physical properties. The methods reported in this study measure a different property more or less related to particle size. Therefore, the differences in the results are attributed to the sediment property measured by the different instruments.

The full dataset was separated in two subsets due to the fact that it was observed the existence of a more or less arbitrary threshold percentage $(6 \%$ in CC). For the first subset $(<6 \%)$ a moderate correlation was found $(r=0.75)$ between the two techniques with the Laser Coulter method slightly overestimating the volume percent. On the other hand, the two methods do not show any correlation for the second subset $(>6 \%)$. The great disparity observed between the two methods in the second subset is due to the samples containing silt-clay mixtures, with well-expressed modal sizes.

\section{Acknowledgements}

The authors would like to thank the geochemical technologist W., Leblanc and sedimentary technician A.O., Brown from the Bedford Institute of Oceanography, Canada, for their great support during the analytical processes. The leading author is supported by the National Scholarships Foundation (NSF) of Greece. 


\section{References}

Balagurunathan, Y., Dougherty, E. R., Frančišković-Bilinski, S., Bilinski, H., and Vdović, N., 2001. Morphological granulometric analysis of sediment images, Image Analysis and Stereology, 20, 87-99.

Behnens, E.W., 1978. Further comparison of grain-size distributions determined by electronic particle counting and pipette techniques, J. Sedim. Petrol., 48, 1213-1218.

Beuselinck, L., Govers, G., Poessen, J., Degraded, G., and Frouen, L., 1998. Grain-size analysis by laser diffractometry: Comparison with the sieve-pipette method, Catena, 32, 193-208.

Bianchi, G.G., Hall, I.L., McCave, I.N., and Joseph, L., 1999. Measurement of the sortable silt current speed proxy using the Sedigraph 5100 and Coulter Multisizer IIe: precision and accuracy, Sedimentology, 46, 1001-1014.

Buurman, P., Pape, T., and Mugger, C.C., 1997. Laser grain-size determination in soil genetic studies: 1. Practical problems, Soil Science, 162, 211-217.

Frančišković-Bilinski, S., Bilinski, H., Vdović, N., Balagurunathan, Y., and Dougherty, E. R., 2003. Application of image-based granulometry to siliceous and calcareous estuarine and marine sediments, Coastal and Shelf Science, 58, 227-239.

Jonasz, M., 1991. Size, shape, composition and structure of microparticles from light scattering. In J.P.M. Syvitski (ed.), Principles, Methods and Application of Particle Size Analysis. 143162pp, Cambridge, Cambridge Univ. Press.

Jordan, C.F., Fryer, J.R., G.E., and Hemmen, E.H., 1971. Size analysis of silt and clay by hydrophotometer, J. Sedim. Petrolog., 41, 489-496.

Iatrou., M., Piper, D.J.W., Tripsanas, E., Papatheodorou, G., and Ferentinos, G., 2006. Man-made gravitational flow deposits: A useful tool for studying the sedimentation processes in a seismically active graben, the Gulf of Corinth, Greece, $17^{\text {th }}$ ISC, Fukuoka, Japan, $27^{\text {th }}$ August-1 ${ }^{\text {st }}$ September, Abstracts book P-063, 279pp.

Konert, M., and Vandenberghe, J., 1997. Comparison of laser grain-size analysis with pipette and sieve analysis: a solution for the underestimation of the clay fraction, Sedimentology, 44, $523-535$.

Loizeau, J.-L., Arbouille, D., Santiago, S., and Vernet, J.-P., 1994. Evaluation of a wide range laser diffraction grain-size analyser for use with sediments, Sedimentology, 41, 353-361.

McCave, I.N., Bryant, R.J., Cook, H.F., and Coughanowr, C.A., 1986. Evaluation of a laserdiffraction-size analyzer for use with natural sediments, J. Sedim. Petrol., 56, 561-564.

McCave, I.N., and Syvitski, J.P.M., 1991. Principles and methods of geological particle size analysis. In J.P.M. Syvitski (ed.), Principles, Methods and Application of Particle Size Analysis, 3-21, Cambridge, Cambridge Univ. Press.

McCave, I.N., Hall, I.L., and Bianchi, G.G., 2006. Laser vs settling velocity differences in silt grainsize measurements: estimation of palaeocurrent vigour, Sedimentology, 53, 919-928.

Milligan, T.G., and Kranck, K., 1991. Electroresistance particle size analyzers. In J.P.M. Syvitski (ed.), Principles, Methods and Application of Particle Size Analysis, 109-118, Cambridge, Cambridge Univ. Press.

Muggler, C.C., Pape, Th., and Buurman, P., 1997. Laser grain-size determination in soil genetic studies: 2. Clay content, clay formation, and aggregation in some Brazilian Oxisols, Soil Sci., 162 (3), 219-228. 
Molinaroli, E., De Falco, G., Rabitti, S., and Portaro, R.A., 2000. Stream-scanning laser system, electric sensing counter and settling grain size analysis: a comparison using reference materials and marine sediments, J. Sedim. Geol., 130, 269-281.

Papatheodorou, G., Stefatos, A., Christodoulou, D., and Ferentinos, G., 2003. Small scale present day turbidity currents in a tectonically active submarine graben, the Gulf of Corinth (Greece): Their significance in dispersing mine tailings and their relevance to basin filling. In J. Locat and J. Mienert (eds), Submarine Mass movements and their consequences. 459468, Netherlands, Kluwer Academic Publishers.

Shideler, G.L., 1976, A comparison of electronic particle counting and pipette techniques in routine mud analysis, J. Sedim. Petrol., 46, 1017-1025.

Singer, J.K., Anderson, J.B., Ledbetter, M.T., McCave, I.N., Jones, K.P.N., and Wright, R., 1988. An assessment of analytical techniques for the size analysis of fine-grained sediments, $J$. Sedim. Petrol,. 58, 534-543.

Sperazza, M., Moore, J.N., and Hendrix, M.S., 2004. High-resolution particle size analysis of naturally occurring very fine-grained sediment through laser diffractometry, J. Sedim. Res., 74 (5), 736-743.

Stein, R., 1985. Rapid grain-size analyses of clay and silt fraction by SediGraph 5000D: comparison with Coulter Counter and Atterberg methods, J. of Sedim. Petrol., 55, 590-593.

Varnavas, S., Ferentinos, G., and Collins, M., 1986. Dispersion of bauxitic red mud in the Gulf of Corinth, Greece, Marine Geology, 70, 211-222.

Van Dongen, W., 1989. Bepaling korrelgrootteverdelingvan waterbodems en zwevende stof. IJking van de laserbuigingsmethode met de zeef- en pipet methode volgens NEN 5753, Afstudeerverslag HLO-chemie. Rijkswaterstaat/RIZA, Lelystad. 